\title{
Modeling of Root-reinforced Soil Slope under Rainfall Condition
}

\author{
Suched Likitlersuang ${ }^{1} *$, Akihiro Takahashi ${ }^{2}$, and Kreng Hav Eab ${ }^{1}$ \\ 1 Geotechnical Research Unit, Department of Civil Engineering, Faculty of Engineering, Chulalongkorn \\ University, 254 Phayathai Road, Wang-Mai, Pathumwan, Bangkok 10330, Thailand \\ 2 Department of Civil Engineering, Tokyo Institute of Technology, M1-3, 2-12-1, Ookayama Meguro-ku \\ Tokyo 152-8552, Japan \\ *E-mail: fceslk@eng.chula.ac.th (Corresponding author)
}

\begin{abstract}
This paper presents the results of geotechnical centrifuge and numerical modeling study of root-reinforced systems on soil slopes. The centrifuge models were designed to simulate a soil slope reinforced by vetiver grass root system commonly grows in Southeast Asian countries. Unreinforced and root-reinforced soil slope models were subjected to heavy rainfall using a rainfall simulator designed for a geotechnical centrifuge. Results of the study show that the root system causes a reduction of rainwater infiltration rate, delay in the response of groundwater table, and increasing in soil shear strength. The results were validated by comparing centrifuge modeling test results with numerical modeling analyses based on limit equilibrium and finite element methods. The transient seepage analysis results were employed in the slope stability analysis. The numerical analysis shows a good agreement in failure mechanisms with the observations from centrifuge modeling tests.
\end{abstract}

Keywords: Centrifuge modeling, slope stability, seepage analysis, landslides, vegetation.

ENGINEERING JOURNAL Volume 21 Issue 3

Received 27 September 2016

Accepted 14 December 2016

Published 15 June 2017

Online at http://www.engj.org/

DOI:10.4186/ej.2017.21.3.123 


\section{Introduction}

Landslides induced by rainfall are one of most serious and common disasters worldwide. In recent years, natural slope instability has increased especially in the tropical monsoon zone such as Southeast Asian countries including Thailand. There are several factors that could cause the natural slope failure, such as geological activity, hydrological influence and human interference, but rainfall is usually the main factor. This is because the change of pore water pressures can be induced by ground water rising or infiltration from the rain water. The increase in pore water pressure shall reduce the matric suction and hence decrease the shear strength of soil in unsaturated zone. The physical process of rainfall infiltration into the ground and its seepage through the soil layers have been studied by hydrogeologists, soil scientist and geotechnical engineers [1].

Vegetation along a slope plays a major role in preventing failure as it can provide both hydrological and mechanical benefits to the stability of natural soil slopes. The role of vegetation on slope stability has been defined by Greenway (1978) [2], Coppin and Richard (1990) [3], Wu (1995) [4] and Gray and Sotir (1996) [5]. For the hydrological process, changing the soil moisture regime and drawing the water from the soil via evapotranspiration [6] could increase the soil suction. For mechanical process, the roots of vegetation could enhance slope stability by increasing the shear strength of the soil $[5,7]$. The benefits of vegetation along natural soil slopes are to prevent shallow failure and soil surface erosion. However, research to understand fundamental mechanisms of root-reinforced soil slopes is limited, particularly for the study of root reinforcement effects on slope stability.

Vetiver grass (Vetiveria nemoralis A. Camus), has been implemented to prevent soil erosion, water runoff, and infiltration by the World Bank in the 1980s [8]. In Thailand, the Chaipattana Foundation and the Office of the Royal Development Projects Board has promoted the use of vetiver grass for soil and water conservation for many royal projects. Vetiver grass is fast growing, cost effective, and requires low maintenance. Chinapan et al. (1997) [9] observed the length of vetiver roots to be up to 2-3.5 $\mathrm{m}$. The vetiver roots can penetrate deep into the ground to form a net-like barrier capable of filtering silt and preserving top soil. In Thailand, slope failure due to prolonged and heavy rainfall typically occurs at shallow depth of approximately 1-1.5 $\mathrm{m}$ from the ground surface. As a result, the use of the vetiver grass root system as slope reinforcement is suitable for preventing slope failure. Root area ratio defined as the ratio between the cross-sectional area of root in the shear plane area and the total area of shear plane, plays an important role contributing to the increase of soil shear strength [5]. Eab et al. (2015) [10] correlated the root area ratio of the vetiver roots with the increase of soil shear strength. The root area ratios of the 4-6 month growth group vetiver were in the range of $2.44-4.56 \%$. The shear strength of soil with vetiver root system was measured by direct shear tests. Results showed that the cohesion of the reinforced soil was increased approximately $11 \mathrm{kPa}$ compared to unreinforced soil.

Centrifuge modeling was implemented in this study because the centrifuge allows modeling of soil slopes with full-scale stress conditions. Few researchers have investigated the mechanism of vegetation for slope stability through the use of a centrifuge. These models simulated the slope failure by continuously raising the groundwater table (e.g. Sonnenberg et al., 2010, 2012) [11, 12]. Some previous researches have investigated the mechanism of rainfall-induced slope failure based on laboratory tests and filed monitoring [13]. However, it is difficult to model the rainfall in a centrifuge. Recently, centrifuge modeling has been used to model rainfall induced landslides to provide a better understanding of the triggering mechanisms of landslides due to rainfall [14-16]. Eab et al. (2015) [10] focused on the application of root-reinforced system to slope stabilization using a rainfall simulator in the centrifuge. In addition, $\mathrm{Ng}$ et al., $(2014,2015)$ $[17,18]$ and Kamchoom et al. (2014) [19] studied the effects of root on transpiration-induced soil suction using centrifuge model.

This paper presents the results of centrifuge and numerical modeling of root-reinforced systems on soil slopes. The results of centrifuge tests carried out by Eab et al. $(2014,2015)[16,10]$ were validated by comparing with numerical modeling simulations. The pore water pressure generation due to transient seepage was used for the slope stability analysis. Input parameters used for the numerical analysis, including volumetric water content, hydraulic conductivity, and shear strength parameters, were obtained from laboratory testing results. Discussions of results from centrifuge and numerical modeling are provided in this paper. 


\section{Centrifuge Model Tests}

Centrifuge modelling is a physical model test and is now widely used in many geotechnical applications. Since slope stability is a gravity-dependent problem, the major advantage of using centrifuge modelling is to enable researchers to test reduced-scale physical models at the correct stress level by increasing g-level [20]. The centrifuge model tests were conducted at Tokyo Institute of Technology in Japan. The tests were performed at a centrifugal acceleration of $50 \mathrm{~g}$. To simulate a heavy rainfall in the centrifuge, a pneumatic nozzle system was designed to spray water over the model slope. Figure 1 shows the schematic of the rainfall simulation system for this study. A brief summary of the experimental details is explained below. More detailed information of centrifuge model tests can be found in Eab et al. $(2014,2015)[16,10]$.

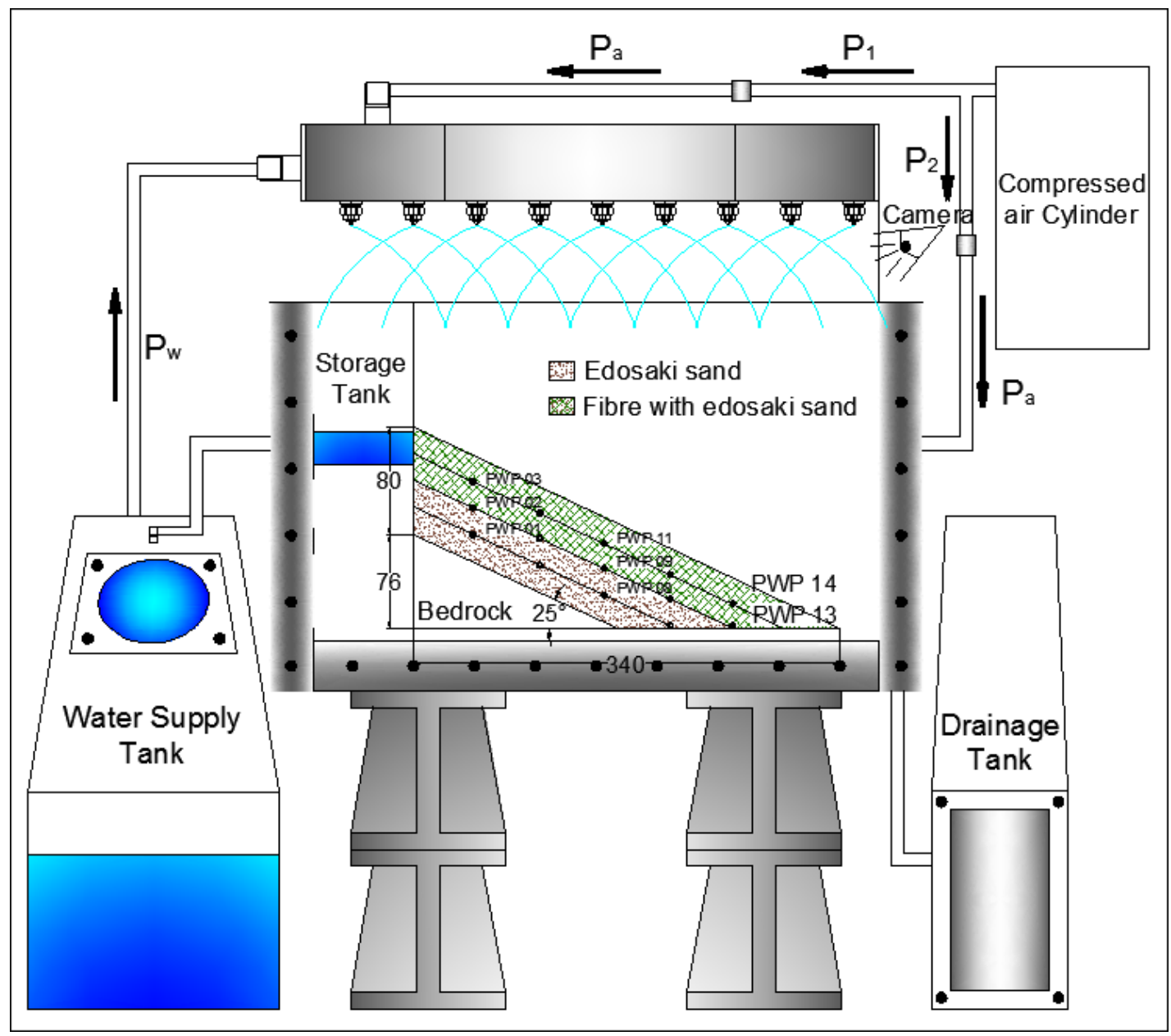

Fig. 1. Schematic centrifuge model with a rainfall simulator system (After Eab et al., 2014) [16].

\subsection{Material Properties}

The Japan Geotecnical Society (JGS) Standard fine sand called Edosaki Sand was used in the model slopes. The engineering properties of the Edosaki sand are summarized in Table 1. The polyester fibers with approximately $39 \mu \mathrm{m}$ in diameter and $10 \mathrm{~mm}$ in length were used to model the root fibers. In the model tests, the $2 \%$ by mass of polyester fibers were randomly mixed with the sandy soil to model the vegetated slope surface. The $2 \%$ fiber mixing by mass is approximately $7 \%$ by volume, which is slightly higher than the root area ratio of vetiver root at 6-months growth reported by Eab et al. (2015) [10]. It is noted that the typical values of the root area ratio of $3-5 \%$ for small vegetation are reported by Gray and Sotir (1996) [5]. The engineering properties of soil mixed with $2 \%$ of polyester fiber are summarized in Table 1. 
Table 1. Properties of compacted soils (After Eab et al., 2014) [16].

\begin{tabular}{lcc}
\hline Soil type & Edosaki Sand & $\begin{array}{c}\text { Edosaki Sand }+ \\
\mathbf{2} \% \text { by mass of } \\
\text { polyester fiber }\end{array}$ \\
\hline Specific gravity, $\mathrm{G}_{\mathrm{s}}$ & 2.65 & - \\
Maximum dry unit weight, $\gamma_{\mathrm{d}}\left(\mathrm{kN} / \mathrm{m}^{3}\right)$ & 12.9 & 12.9 \\
Optimum water content, $w_{\text {opt }}(\%)$ & 15.2 & 17.3 \\
Degree of saturation, $S_{\mathrm{r}}(\%)$ & 39.9 & - \\
Total unit weight, $\gamma_{\mathrm{t}}\left(\mathrm{kN} / \mathrm{m}^{3}\right)$ & 14.9 & 15.2 \\
Void ratio, $e$ & 1.01 & - \\
Maximum void ratio, $e_{\max }$ & 1.29 & - \\
Minimum void ratio, $e_{\min }$ & 0.87 & - \\
Saturated hydraulic conductivity, Ksat $(\mathrm{cm} / \mathrm{s})$ & $3.25 \times 10^{-5}$ & $3.08 \times 10^{-5}$ \\
Cohesion intercept, $c(\mathrm{kPa})$ & 4.8 & 18.9 \\
Angle of shearing resistance, $\phi(\circ)$ & 28.6 & 31.5 \\
\hline
\end{tabular}

Shear strength of soil was examined by a standard $60-\mathrm{mm}$ diameter direct shear apparatus. Edosaki sand was prepared to achieve a relative density of $80 \%$ and water content of $15 \%$. For a mixture of sand and fiber roots, the sample was prepared at the same degree of compaction but at a water content of $17 \%$. The direct shear tests were carried out to determine the angle of shearing resistance $(\phi)$ and the cohesion intercept (c) of the Edosaki sands with and without fibers. By adding $2 \%$ of polyester fiber into the sand, the cohesion and friction angle of the mixture are increased by approximately $14 \mathrm{kPa}$ and $3^{\circ}$ respectively as presented in Table 1. It is noted that the sands were prepared in unsaturated state. Therefore, the shear strength parameters reported in Table 1 are the "apparent" shear strength parameters. However, this result is comparable with the direct shear test results of vetiver root system from Eab et al. (2015) [10]. It is also observed that the coefficient of permeability of the soil and fiber mixture was slightly lower than that of the soil without fibers.

\subsection{Slope Model Tests}

The slope model was constructed inside a $450 \mathrm{~mm} \times 150 \mathrm{~mm} \times 270 \mathrm{~mm}$ steel box. The model design is schematically illustrated in Fig. 1. Three model cases, i.e., Case 1: without reinforcement, Case 2: with 20$\mathrm{mm}$ fiber reinforcement and Case 3: with 40- $\mathrm{mm}$ fiber reinforcement, were conducted and summarized in Table 2.

Table 2. Summary of centrifuge tests (After Eab et al., 2014) [16].

\begin{tabular}{ccccc}
\hline $\begin{array}{c}\text { Case } \\
\text { No. }\end{array}$ & Model Description & Setup & $\begin{array}{c}\text { Test duration } \\
\text { (hr) }\end{array}$ & Remarks \\
\hline 1 & Unreinforced & Bare soil & 18 & Slope collapsed \\
2 & $\begin{array}{c}\text { 20-mm thick of fiber- } \\
\text { reinforced surface layer } \\
\text { 40-mm thick of fiber- } \\
\text { reinforced surface layer }\end{array}$ & 2-m depth of vegetation root & 40 & $\begin{array}{c}\text { Moderate deformed } \\
\text { (Not collapsed) } \\
\text { Small deformed } \\
\text { (Not collapsed) }\end{array}$ \\
\hline
\end{tabular}

To examine the reinforcing effect of the roots against slope failure, the rooting depth is selected as a parameter. The slope model consists of bedrock and soil slope. The bedrock with $165 \mathrm{~mm}$ in length $(8.25 \mathrm{~m}$ in the prototype), $76 \mathrm{~mm}$ in height $\left(3.8 \mathrm{~m}\right.$ in the prototype) and slope angle of $25^{\circ}$ was made of aluminum plates and placed on a $10 \mathrm{~mm}$-thick acrylic plate. The surface of bedrock was roughened by attaching a sand 
paper. The soil slope consists of four layers of Edosaki sand with a total thickness of $80 \mathrm{~mm}$. Pore water pressure transducers (PWPs) and accelerometers (ACCs) were installed in the soil layers during the compaction to measure the pore water pressure and the soil slope displacement. The soil displacements were measured and a testing video was recorded through the transparent front side of the model container. During the test, a rainfall intensity of $1000 \mathrm{~mm} / \mathrm{h}(20 \mathrm{~mm} / \mathrm{h}$ in the prototype) classified as heavy rainfall [21] was applied to simulate rainfall over the slope surface. Pore water pressure and soil displacement were continuously recorded during the test. It is noted that the tests were stopped when the collapse of slope or dam-up water at the toe slope was observed.

\subsection{Results of Centrifuge Tests}

Results showed that the unreinforced slope failed due to the rising groundwater table. It was observed that the failure started to deform from the toe and progressively propagate upward to the top of the slope. Both root-reinforced slopes deformed but did not collapse. The tests were terminated when the failure of the slope was observed or the pressure head at the toe slope reached the critical value. The centrifuge test results are summarized in Table 2. Results indicated that the existence of root fibers helps increase the soil strength and reduce the infiltration rate of rainfall into the ground, resulting in a delayed response in the groundwater table. In other words, roots can delay slope failure and slow movement of a soil slope could provide a first early warning of failure. More detailed discussions of the centrifuge results can be found in Eab et al. (2014) [16].

\section{Slope Stability Analysis}

Numerical analysis is commonly carried out to validate the results of physical modeling tests and to better understand the effect of suction loss due to rainfall infiltration on slope stability. In this study, the three cases similar to the centrifuge tests were modeled. Each model was performed by using transient analysis to define the pore water pressure change in the soil slope. Based on the pore water pressure information, the factor of safety of the soil slope was calculated using the limit equilibrium methods.

\subsection{Seepage and Slope Stability Modeling}

Two-dimensional seepage and slope stability analyses were performed using GEO-SLOPE software [22]. Simplified homogenous slope profiles for each soil layer were used in the study. For a transient analysis in seepage, the soil-water characteristic curve (SWCC) and the hydraulic conductivity function are required input parameters. The estimation method to determine the SWCC proposed by Aubertin et al. (2003) [23] was chosen in this analysis. The proposed model assumes that soil-water characteristic results from the combined effect of capillary and adhesion forces. The SWCC can be evaluated from the negative pore water pressure and material property information such as particle-size distribution. In addition, the hydraulic conductivity function can also be estimated using several predictive methods that utilize either a grain-size distribution or a measured volumetric water content function and the saturated hydraulic conductivity (Ksat). In SEEP/W, a built-in predictive method can be used to estimate the hydraulic conductivity function once the volumetric water content function and a Ksat value have been specified. More details of the assumptions of the predictive methods to estimate the SWCC and the hydraulic conductivity function can be seen in the SEEP/W manual [22]. Figures 2(a) and 2(b) present the SWCC and the hydraulic conductivity function used in this study.

The initial total head was defined by specifying the initial water table position at the base of the toe slope. The negative pore water pressure in the unsaturated zone above the water table varies in a linear manner from zero at the base of the toe slope to the maximum value at the surface. For the rainfall simulation, the flux boundary, $q$ equal to the desired rainfall intensity of $20 \mathrm{~mm} / \mathrm{hr}$ was applied to the surface of the slope. The potential seepage face was also applied at the toe of the slope model. Figure 3 presents the geometry boundary and the initial water pressure conditions for the seepage and slope stability analyses. The pore water pressures were calculated for every time step at each node of the finite-element mesh. The pore water pressure results from SEEP/W were then incorporated into the SLOPE/W model. Slope stability analyses were performed using Bishop's simplified and Morgenstern-Price methods. The input parameters from the direct shear tests shown in Table 1 were used for the slope stability analyses. 


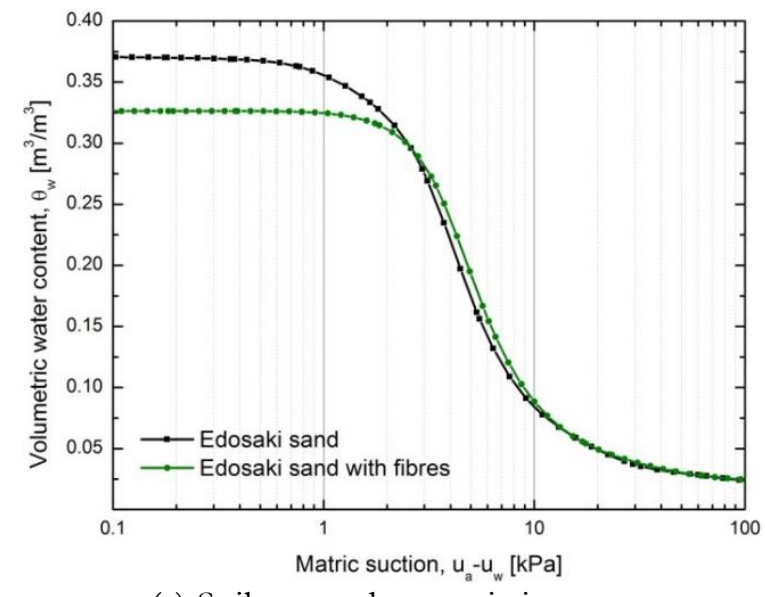

(a) Soil water characteristic curve

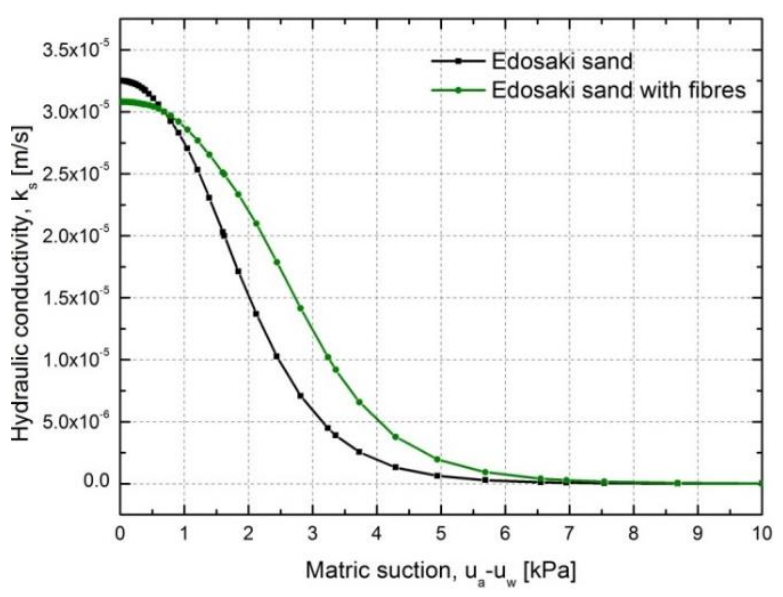

(b) Hydraulic conductivity

Fig. 2. Input soil water characteristic curve and hydraulic conductivity for seepage analysis

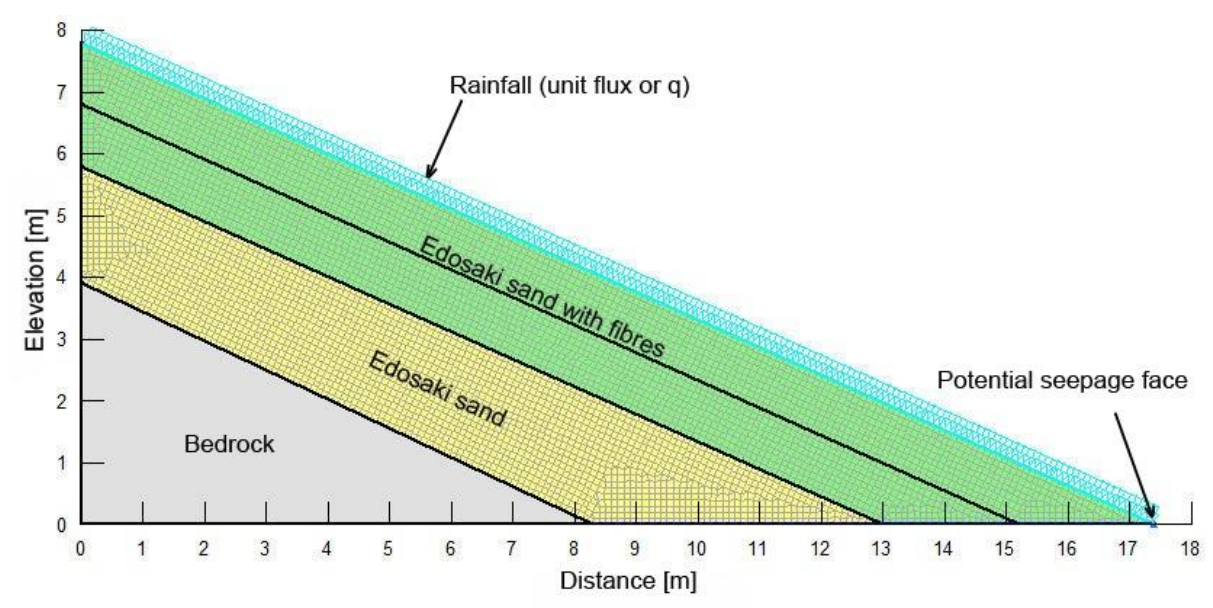

(a) Geometry boundary condition

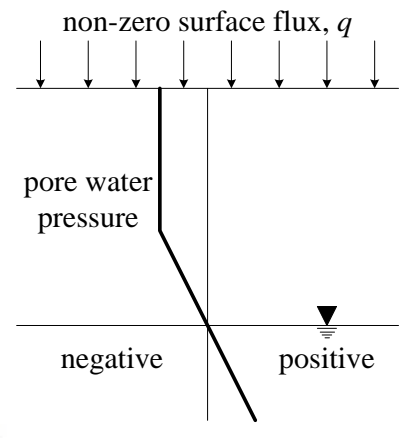

(b) Initial pore water pressure condition

Fig. 3. Boundary and initial conditions for seepage and stability analyses

\section{Results and Discussion}

\subsection{Pore Water Pressure Distribution}

Figure 4 shows the pore water pressure contour distribution in the soil slope simulated by the seepage analysis for the three different cases. Results showed that during rainfall, pore water pressure in the soil slope initially started from negative and then moved gradually towards positive values. Figure 4(a) shows the result of the unreinforced case, where the pore water pressure increased by $10 \mathrm{kPa}$ at the toe of the slope while at the top slope pressure remained negative after an $18 \mathrm{hr}$ duration of rainfall. For the case of 1 $\mathrm{m}$ depth of vegetation, shown in Fig. 4(b), the large amount of rainwater infiltrated into the slope and changed the pore water pressure from negative to positive value of $20 \mathrm{kPa}$ after $35 \mathrm{hr}$. For the case of $2-\mathrm{m}$ depth of vegetation, shown in Fig. 4(c), pore water pressure increased up to $25 \mathrm{kPa}$ after $40 \mathrm{hr}$. Based on these results, it is observed that pore water pressure increased to the critical values when the slope started to fail or deform significantly.

\subsection{Slip Surface for Factor of Safety}

Figure 5 shows the potential slip surface and ground water table simulated by SLOPE/W. Due to the increase of cohesion by the root reinforcement, the slip surface for the root-reinforced slope was mostly 
developed near the bedrock, especially for the case of 2-m depth of vegetation (Fig. 5(c)), in comparison with the slip surface of the unreinforced slope that was developed at shallower depth (Fig. 5(a)). The reason of this occurs is because the shear strength of the soil and root fiber at the top layer is higher than the soil only at the bottom layer. In addition, it was found that the factor of safety (FS) is slightly increased for the reinforced soil slopes as summarized in Table 3. According to the results, the shear strength of unsaturated zone decreased and consequently the FS of the slope reduced during the rainfall. Comparing the FS at the same duration of rainfall, the FS increases with the depth of roots for the root-reinforced cases.

Table 3. Factors of safety from numerical analysis

\begin{tabular}{|c|c|c|c|c|c|}
\hline \multirow{2}{*}{\multicolumn{2}{|c|}{ Case }} & \multirow{2}{*}{ Circular failure method } & \multicolumn{3}{|c|}{ Duration of rainfall (hr) } \\
\hline & & & $18 \mathrm{hr}$ & $35 \mathrm{hr}$ & $40 \mathrm{hr}$ \\
\hline \multirow{2}{*}{\multicolumn{2}{|c|}{ Unreinforced slope }} & Bishop & 1.76 & - & - \\
\hline & & Morgenstern-Price & 1.77 & - & - \\
\hline \multirow{4}{*}{$\begin{array}{l}\text { Root- } \\
\text { reinforced } \\
\text { slope }\end{array}$} & \multirow{2}{*}{ 1-m depth } & Bishop & 2.05 & 1.82 & - \\
\hline & & Morgenstern-Price & 2.09 & 1.87 & - \\
\hline & \multirow{2}{*}{ 2-m depth } & Bishop & 2.29 & 2.01 & 1.89 \\
\hline & & Morgenstern-Price & 2.31 & 2.01 & 1.90 \\
\hline
\end{tabular}

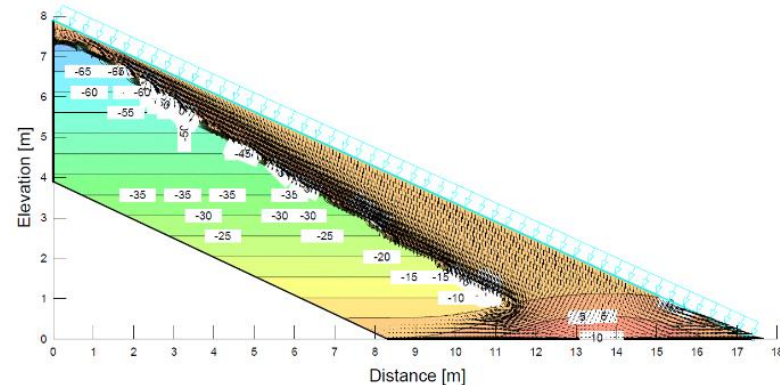

(a) Case 1: unreinforcement

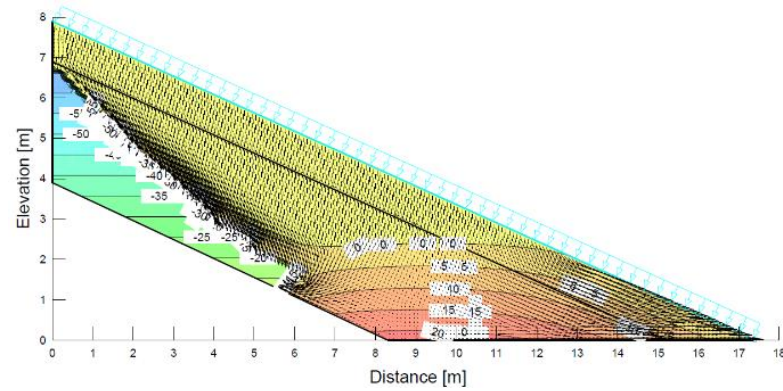

(b) Case 2: $1 \mathrm{~m}$ depth of root

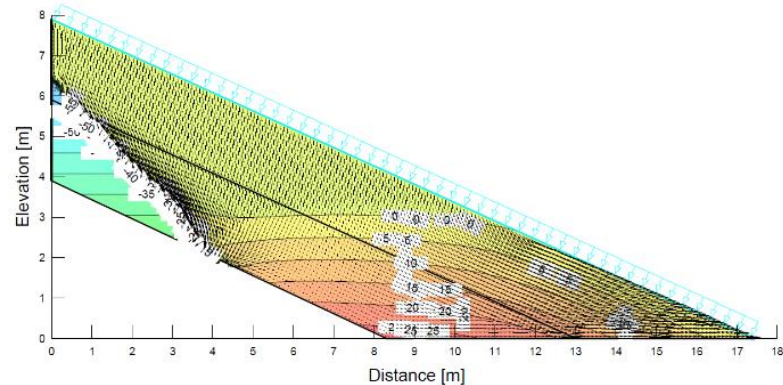

(c) Case 3:2m depth of root

Fig. 4. Results pore water pressure change at the end of test.

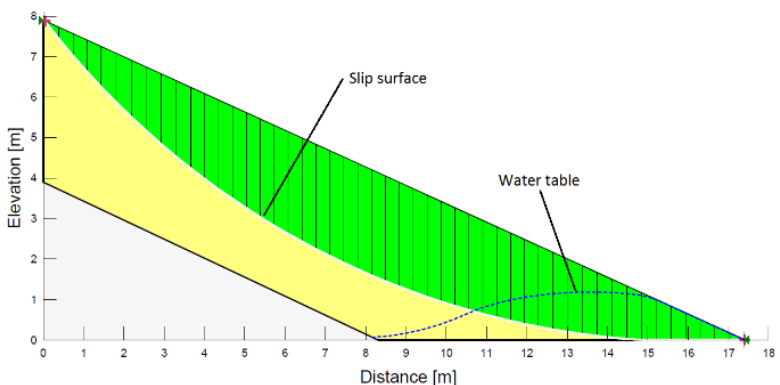

(a) Case 1: unreinforcement

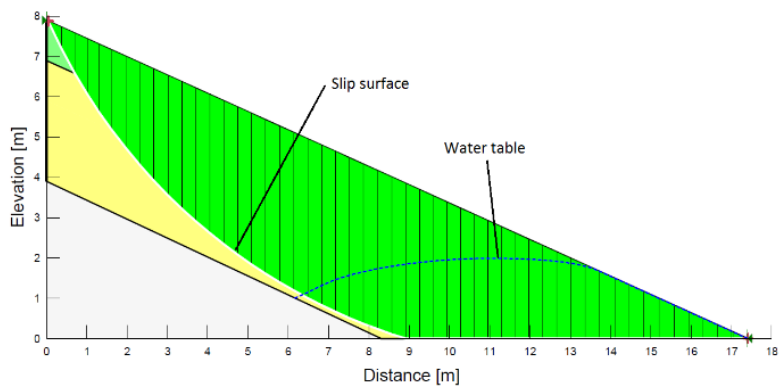

(b) Case 2: $1 \mathrm{~m}$ depth of root

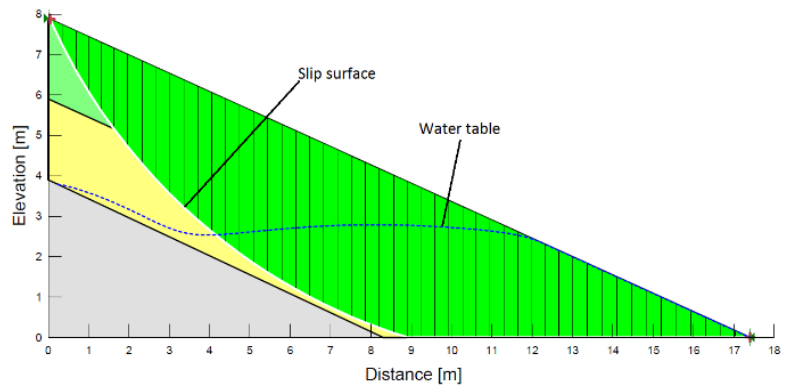

(c) Case 3:2m depth of root

Fig. 5. Results slip surface at the end of test. 


\section{Centrifuge model}
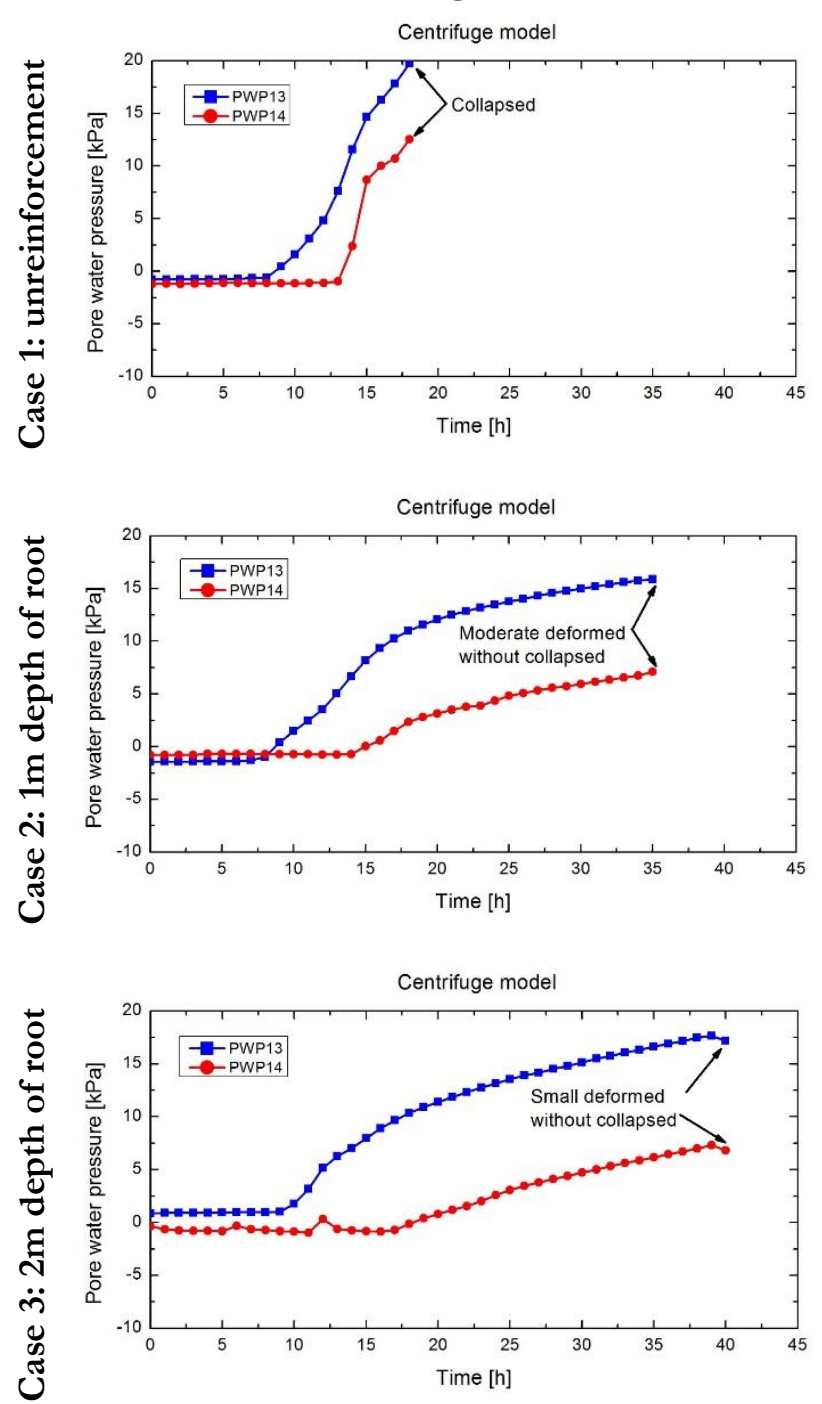

\section{Numerical model}
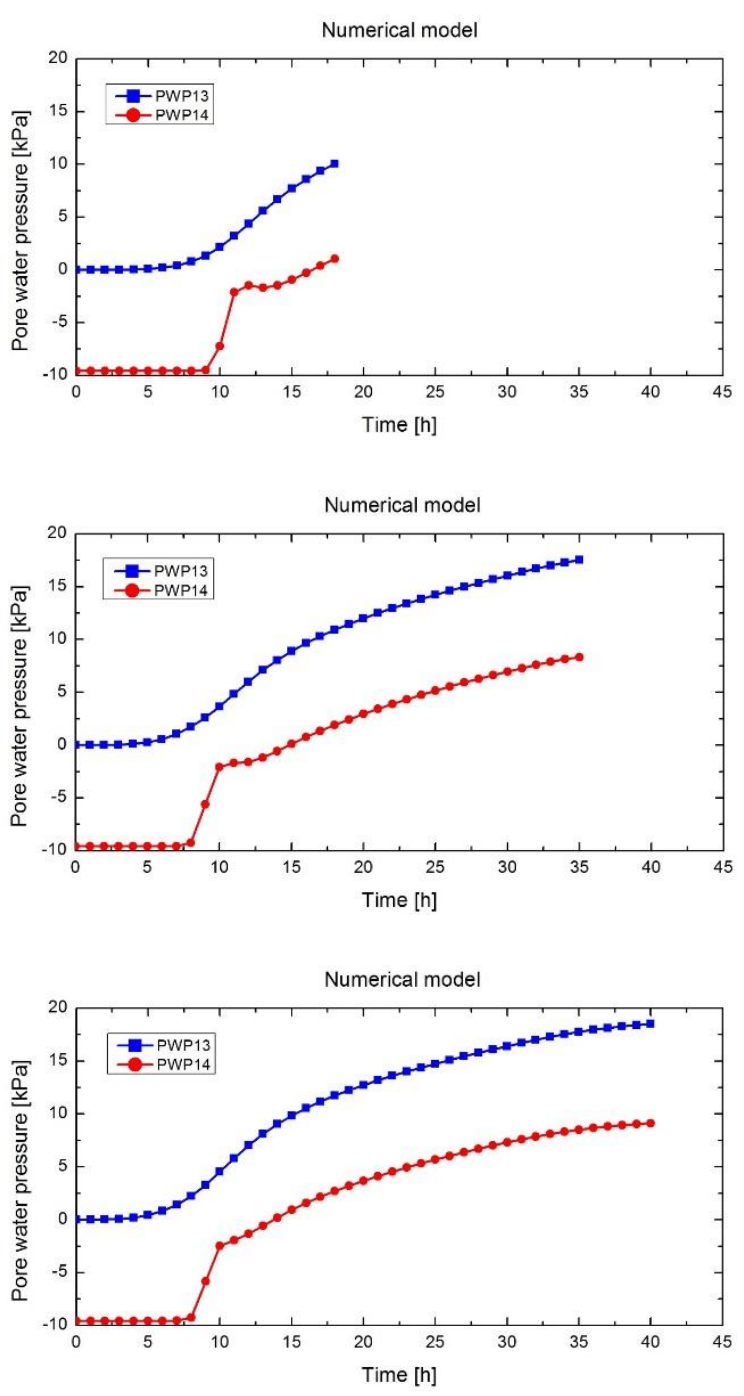

Fig. 6. Comparison of pore water pressure change between centrifuge test and numerical analysis.

\subsection{Comparison of Centrifuge and Numerical Modeling Results}

Figure 6 shows a comparison of pore water pressure between the centrifuge test and numerical analysis for the unreinforced case, 1-m depth of root case, and 2-m depth of root case. Pore water pressure measured by PWP 13 and PWP 14, which are located near the toe of the slope were plotted with time during the continuous rainfall. The increase of the pore water pressure was used to indicate the triggering time for slope failure as summarized in Table 2. Buildup of pore water pressure for the unreinforced slope is faster than for the root-reinforced slopes. For the unreinforced case, the pore water pressures measured from the centrifuge are much higher than the numerical values. As a result, the factor of safety calculated from the numerical model is higher than expected. This might be due to the fact that the numerical analysis results rely on the input parameters and boundary conditions. In this analysis, assumptions of the SWCC and hydraulic conductivity were made. Despite this, the comparisons show a reasonable agreement between the centrifuge and numerical results with the exception of the negative value measured at PWP 14. This is due to the limitation of pore water pressure transducer installed in the centrifuge test which cannot accurately measure negative pore water pressure. Based on this study, results from both centrifuge and numerical modeling provide good insight into the mechanisms of vegetated root reinforced slope during rainfall. The root-reinforced system delays the rising of the groundwater table and increases the factor of safety of the slope. 


\section{Conclusions}

This research evaluated the effects of vegetation root on slope stability. A series of centrifuge model tests on slopes reinforced by the root model were conducted to illustrate the advantage of the vegetation on the rainfall-induced shallow failure. The results of centrifuge tests were verified by the numerical simulations. Conclusions from this study are as follows.

1) The centrifuge model with rainfall simulator was employed to illustrate the slope instability due to heavy rainfall. The slope failure is triggered by rising of the water table and starts around the toe of the slope. The increase in pore water pressures from water table causes the decrease in the effective stress and shear strength of the soil.

2) The polyester fiber mixed soil can be reasonably used to model the vegetated soil slope in the centrifuge. The results showed that roots in the surface of a slope tie the soil particles together and prevent the formation of cracks on the slope surface. The reinforcement efficiency increases with the root depth and the thicker reinforced zone reduces the slope deformation. In addition, the roots can delay the infiltration of rainfall into the ground to delay the rising of the groundwater table. The delay of slope failure or movement could provide an early warning for evacuation.

3) Results from numerical analyses show an agreement with the results observed in centrifuge model tests. The factor of safety of the slope increases as the depth of root reinforcement increases. The mixture of soil and fiber roots increase the shear strength of soil, hence it provides overall improvement of the slope stability.

\section{Acknowledgements}

This research was supported by the Thailand Research Fund under the TRF Research Scholar Award Grant No. RSA-5880023. The work was also carried out under the research and development project on landslide prevention and protection according to Royal Initiatives of the Chaipattana Foundation. The authors would like to thank Dr. Inthuorn Sasanakul for her comments to improve the manuscript.

\section{References}

[1] C. W. W. Ng and Q. Shi, "A numerical investigation of the stability of unsaturated soil slope subjected to transient seepage," Computer and Geotechnics, vol. 22, no. 1, pp. 1-28, 1998. doi:10.1016/S0266352X(97)00036-0

[2] D. R. Greenway, "Vegetation and slope stability," in Slope Stability, M. G. Anderson and K. S. Richards, Eds. New York, NY: John Wiley and Sons, 1978.

[3] N. J. Coppin and I. G. Richards, Use of Vegetation in Civil Engineering Construction Industry and Research Information Association (CIRLA). London: Butterworths, 1990.

[4] T. H. Wu, "Slope stabilization," in Slope Stabilization and Erosion Control, R. P. C. Morgan and R. J. Rickson, Eds. London: E\&FN Spon, 1995.

[5] D. H. Gray and R. B. Sotir, Biotechnical and Soil Bioengineering Slope Stabilization: A Practical Guide for Erosion Control. New York: John Wiley \& Sons, 1996.

[6] F. H. Ali and N. Osman, "Shear strength of a soil containing vegetation roots," Soils and Foundations, vol. 48, no. 4, pp. 587-596, 2008.

[7] T. H. Wu, W. P. McKinnell, and D. N. Swanston, "Strength of tree roots and landslides on Prince of Wales Island, Alaska," Canadian Geotechnical Journal, vol. 16, pp. 19-33, 1979.

[8] J. C. Greenfield, "Vegetative vs. mechanical soil conservation system as they affect moisture conservation and sustained production," in Proceedings of the First International Conference on Vetiver, Office of the Royal Development Projects Board, Bangkok, 1996, pp. 1-7.

[9] W. Chinapan, A. Sukhasem, and L. Moncharoen, A Study on the Ecotype Comparison of Vetiver Grass in Thailand. Land Development Department, Ministry of Agriculture and Cooperatives, Thailand, 1997.

[10] K. H. Eab, S. Likitlersuang, and A. Takahashi, "Laboratory and modelling investigation of rootreinforced system for slope stabilization," Soils and Foundations, vol. 55, no. 5, pp. 1270-1281, 2015. doi:10.1016/j.sandf.2015.09.025 
[11] R. Sonnenberg, M. F. Bransby, P. D. Hallett, A. G. Bengough, S. B. Mickovski, and M. C. R. Davies, "Centrifuge modelling of soil slopes reinforced with vegetation," Canadian Geotechnical Journal, vol. 47, pp. 1415-1430, 2010. doi:10.1139/T10-037

[12] R. Sonnenberg, M. F. Bransby, A. G. Bengough, P. D. Hallett, and M. C. R. Davies, "Centrifuge modelling of soil slopes containing model plant roots," Canadian Geotechnical Journal, vol. 49, pp. 1-17, 2012. doi:10.1139/t11-081

[13] H. Chen, C. F. Lee, and K. T. Law, "Causative mechanisms of rainfall-induced fill slope failures," ASCE Journal of Geotechnical and Geoenvironmental Engineering, vol. 130, no. 6, pp. 593-602, 2004.

[14] H. Ling and H. Ling, "Centrifuge model simulations of rainfall-induced slope instability," Journal of Geotechnical and Geoenvironmental Engineering, vol. 138, no. 9, pp. 1151-1157, 2012. doi:10.1061/(ASCE)GT.1943-5606.0000679

[15] A. Takahashi, K. Nakamura, and S. Likitlersuang, "On the seepage-induce failure of vegetationstabilised slopes," in Proceeding of the 8th International Conference on the Physical Modelling in Geotechnic, Gudin \& White, Eds. London: Taylor \& Francis Group, 2014, pp. 1233-1239.

[16] K. H. Eab, A. Takahashi, and S. Likitlersuang, "Centrifuge Modelling of root-reinforced soil slope subjected to rainfall infiltration," Geotechnique Letters, vol. 4, pp. 211-216, 2014. doi:10.1680/geolett.14.00029

[17] C. W. W. Ng, A. K. Leung, V. Kamchoom, and A. Garg, "A novel root system for simulating transpiration-induced soil suction in centrifuge," Geotechnical Testing Journal, vol. 37, no. 5, pp. 1-15, 2014. doi:10.1520/GTJ20130116

[18] C. W. W. Ng, V. Kamchoom, and A. K. Leung, "Centrifuge modelling of the effects of root geometry on transpiration-induced suction and stability of vegetated slopes," Landslides, vol. 13, no. 5, pp. 925938, 2016. doi:10.1007/s10346-015-0645-7

[19] V. Kamchoom, A. K. Leung, and C. W. W. Ng, "Effects of root geometry and transpiration on pullout resistance," Géotechnique Letter, vol. 4, pp. 330-336, 2014. doi:10.1680/geolett.14.00086

[20] R. N. Taylor, Geotechnical Centrifuge Technology. Taylor and Francis, 1995.

[21] M. C. Llasat, "An objective classification of rainfall events on the basis of their convective features: Application to rainfall intensity in the northeast of Spain," International Journal of Climatology, vol. 21, no. 11, pp. 1385-1400, 2001.

[22] GEO-SLOPE, Stability Modeling with SLOPE/W 2007 Version-An Engineering Methodology, 4th ed. Alberta, Canada: GEO-SLOPE International, Ltd., Nov. 2008.

[23] M. Aubertin, M. Mbonimpa, B. Bussière, and R. P. Chapuis, "A model to predict the water retention curve from basic geotechnical properties," Canadian Geotechnical Journal, vol. 40, no. 6, pp. 1104-1122, 2003. doi: $10.1139 / \mathrm{t} 03-054$ 